\title{
Effects of E-Learning System on Teacher Orientation Programs: A Case Study of Kenya Institute of Education
}

\author{
Geoffrey Rotich, Benjamin Kyambo, Fredrick M. Awuor, Felix Obegi \\ Faculty of Information Science and Technology, Kisii University, P. O. Box 408-40200 Kisii, Kenya \\ *Corresponding Author: fredrickawuor@gmail.com
}

Copyright $@ 2013$ Horizon Research Publishing All rights reserved.

\begin{abstract}
Tremendous advances in computer technology and the evolution of the Internet have led to new approaches in learning and training which are summarized under the term e-Learning. This research studied the effects of e-learning system on teacher orientation programs conducted by Kenya Institute of Education (KIE), which is a National Curriculum Development and Research Centre, offers online teacher orientation courses using Elimika learning management system. The objectives of this study were to establish the extent of use of e-learning system by teachers in curriculum orientation programs, assess teachers' perceptions, identify challenges and establish possible mechanisms that can be put in place to encourage teachers to use e-learning system in curriculum orientation programs. Theoretical framework for the study was Technology Acceptance Model which postulates that a person's behavioural intention to use e-learning is determined by perceived usefulness and ease of use. The population consisted of 800 primary school teachers enrolled in Elimika e-learning system and 124 curriculum developers working at KIE. Stratified random sampling was used to select a sample of 214 teachers and 110 curriculum developers. The curriculum developers who responded to the questionnaire were 198 and teachers were 80 representing a response rate of 92.52 percent and 72.73 percent respectively. Data was collected using questionnaires and analyzed using Statistical Package for Social Sciences version 19. The study found out that e-learning system features such as ease of use, interactivity and flexibility had significant total effects upon usage by teachers in curriculum orientation. Also teachers' perceptions on the appropriate content, saving on time and effort, learning enhancement and enjoyment had a significant effect on intention to use Elimika system. The study also identified various challenges encountered by teachers and some mechanisms that can be put in place to encourage teachers to use e-learning system. Slow internet connectivity, network downtime and lack of computers were the main challenges encountered by teachers when using Elimika e-learning system.
\end{abstract}

Keywords E-Learning, Teacher, Kenya Institute of Education

\section{Introduction}

The technological revolution in information technology has led to rapid growth in all fields of knowledge making it an imperative requirement for educational institutions to improve learning environments as well as cope with the ever increasing demand for education and training. Coldwell (2008) describes e-learning as the online learning and the networked learning. E-learning comprises all forms of electronically supported learning and teaching. It covers a wide range of instructional material that can be delivered on a CD-ROM or DVD, over a local area network (LAN), or on the Internet. Kenya Institute of Education (KIE) is a State Corporation under the Ministry of Education established through Legal Order 120 of 2010 under the State Corporation Act CAP 446, of the Laws of Kenya. The Institute's core function is to conduct research and develop curricula for all levels of education below the university. KIE offers online teacher orientation courses using Elimika Learning Management System (LMS) that is being used to host the courses. The system allows for interactivity through discussion forums, chats and e-mail, testing and feedback in form of answers as well as grading. It integrates an intelligent tutoring system, a computer instruction management system and a set of cooperative tools.

This study endeavoured to find out the effects of e-learning system on teacher orientation programs. The general objective of this study was to examine the effects of e-learning system on teachers' orientation programs,identify challenges and provide possible solutions.Specific objectives of this study were:

i. To establish the extent of use of e-learning system by teachers in curriculum orientation programs.

ii. To assess teachers' perceptions on the use of e-learning system in curriculum orientation.

iii. To identify the challenges encountered by teachers when using e-learning system in curriculum orientation programs.

iv. To establish possible mechanisms that can be put in 
place to encourage teachers to use e-learning system in curriculum orientation programs

The study was guided by the following research questions:

i. What is the extent of use of e-learning system by teachers in curriculum orientation programs?

ii. What are the main perceptions of teachers using e-learning system?

iii. What are the challenges faced by teachers when using e-learning system for curriculum orientation?

iv. How can teachers be motivated to use the e-learning system for curriculum orientation?

\section{Significance of the Study}

The findings from this study provided insight into the situation on the ground on extent of use, perceptions, challenges and recommendations on how to motivate teachers to embrace e-learning system for curriculum orientation. The study also provided useful information that would assist stakeholders in the education sector to better design and implement e-learning strategies. The Government of Kenya, through the Ministry of Education, would be able to use the findings of this study to formulate policies governing e-learning programs targeting teachers and other curriculum implementers. The findings and recommendations from this research would add to the field of knowledge on e-learning technology and utilization. The research findings could also serve as baseline survey for future studies on the effect, roles or impact of e-learning technologies in various levels of education.

\section{Related Work}

E-learning has been defined in different ways. According to Meyen et al. (2002), e-learning can be defined as the acquisition and use of knowledge distributed and facilitated by electronic means. Khan (2005) defines e-learning as an innovative approach for delivering well-designed, learner-centered, interactive, and facilitated learning environment to anyone, anyplace, anytime by utilizing the attributes and resources of various digital technologies along with other forms of learning materials suited for open, flexible, and distributed learning environment.

Curriculum implementers' must be equipped with critical and analytical tools necessary to live and flourish in information saturated environment. Curriculum is dynamic and changes are inevitable. To ensure that curriculum implementers are in tandem with the dynamic nature of curriculum itself there is need to use technology which ensures that content is regularly up dated and that implementers are regularly in serviced on new and emerging issues within the existing curriculum. It is with this realization that the Kenya Institute of Education (KIE) has set up a Learning Management System known as Elimika and whose main aim is to increase access to information on issues relating to the curriculum and curriculum delivery (Kenya Institute of Education, 2011).

The Elimika system is the vehicle through which Kenya Institute of Education (KIE) delivers its courses. The system has been in use for five years. The name Elimika is a Kiswahili word meaning "get educated" which was coined to capture the idea behind online training and also give it a Kenyan identity. The Learning Management System (LMS) is supported by a community of experts and is always under review to be in tandem with the ever changing technology.The platform allows development of content within it and also allows importation of content authored in other software. The exe authoring tool is used to develop content which is then loaded onto the LMS. The system is a Web 2.0 enabled rapid application development framework for creating web applications that are platform independent, browser independent and can use a number of common databases. It also accommodates the use of multimedia such as illustrations, animations, photographs and videos which enhance interactivity. Other tools within the system which enhance interactivity include discussion forums where the participants discuss various issues guided by the online tutors, chats, internal mail, announcementboards where announcements concerning the courses are made including the term dates, exams and blogs.

This study used Technology Acceptance Model (TAM) as its theoretical framework. The TAM model was developed by Davis (1991). TAM model was built upon Fishbein and Ajzen's (1975) Theory of Reasoned Action (TRA) which postulates that beliefs could influence attitudes, which lead to intention to use and finally actual usage behavior. TAM as proposed by Davis (1991) describes that a person's behavioural intention to use e-learning is determined by perceived usefulness and perceived ease of use. Although TAM's ultimate goal is actual usage, it could also be used to explain why individuals may accept or not accept a particular technology such as e-learning (Jung, 2008). This research on the effects of e-learning system on teacher orientation programs was therefore applicable to this model as it deals with user perception and usage of the system(Davis, 1991). However this model as it is, doesnot present all the important components for the acceptance, adoption and usage of e-learning system for curriculum orientation. This study therefore adjusted the technology acceptance model toinclude components of ease of adoption, access to infrastructure and experiences.

\section{Research Design}

A research design is the plan and structure of investigation so conceived as to obtain answers to research questions. It is the 'glue' that holds together all the elements in a research project (Kombo and Tromp, 2006). This study employed a descriptive survey design. A survey is essentially an appraisal study seeking to reveal the present truth and suggest a possible course of action for the phenomenon 
observed. Mugenda (2008) states that survey designs are used to collect information that describe, explore and help the researcher to determine cause and effect between variables such as in this study which sought to find out if the e-learning system has had an effect on the teachers' orientation programs conducted by KIE. The target population was made up of primary school teachers enrolled in Elimika e-learning system and curriculum developers working at KIE. It comprised of 800 primary school teachers enrolled in the Elimika LMS and 124 curriculum developers Kenya Institute of Education, 2011). Sampling is a process of selecting a number of individuals or objects from a population such that the selected group contains elements representative of the characteristics found in the entire group (Orodho and Kombo, 2002). Stratified random sampling was used to select primary school teachers enrolled in Elimika e-learning system and KIE curriculum developers. In stratified random sampling technique, a population is divided into subgroups called strata and a random sample is selected from each stratum (Mugenda, 2008). The sample size was calculated using the following formula by Calmorin, et al. (2007).

$$
\mathrm{SS}=\frac{\mathrm{NV}+\left[\mathrm{Se}^{2}(1-\mathrm{P})\right]}{\mathrm{NSe}+\left[\mathrm{V}^{2} \times \mathrm{P}(1-\mathrm{P})\right]}
$$

Where SS - sample size, $\mathrm{N}$ - total number of population, $\mathrm{V}$ the standard value of 2.58 , Se - sampling error of 0.01 and $\mathrm{P}$ the largest possible proportion of 0.50 .

From the teachers' population of 800 , the sample size was obtained as follows:

$$
\mathrm{SS}=\frac{800+\left[(0.01)^{2}(1-0.50)\right]}{800(0.01)+\left[2.58^{2} \times 0.50(1-0.50)\right.}=214
$$

From the curriculum developers' population of 124, the sample size was obtained as follows:

$$
\mathrm{SS}=\frac{125+\left[(0.01)^{2}(1-0.50)\right]}{125(0.01)+\left[2.58^{2} \times 0.50(1-0.50)\right.}=110
$$

The researcher used questionnaires in this study. The reason for choosing the questionnaires as the data collection instrument was primarily due to its cost effectiveness, practicability and applicability to the research problem and the size of the population. Furthermore, using questionnaires ensure that confidentiality is upheld; they save on time and have no interviewer bias (Kombo and Tromp, 2006).

\section{Results and Discussion}

A total of $278(88.54 \%)$ respondents out of the 324 sampled responded to the questionnaire. Out of 214 primary school teachers and 110 curriculum developers, 198 teachers and 80 curriculum developers responded, representing a response rate of $92.52 \%$ and $72.73 \%$ respectively. According to Creative Research Systems (2013) this response rate was acceptable for the research since the worst case scenario is a $50.00 \%$ response.

Chi-Square test was used to check whether there is any relationship between the respondents' characteristics and ease of use of Elimika e-learning system. The result is presented in table 1. It shows significant relationships for gender and teaching experience while age and highest academic qualification has little or no close association with ease of use of Elimika system.

Table 1. Relationship between respondent's characteristics and ease of use of Elimika E-learning system

\begin{tabular}{cccc}
\hline Respondent's Characteristics & Value & df & Sig. \\
\hline Gender & $2.905 \mathrm{a}$ & 1 & .088 \\
Age & $1.941 \mathrm{a}$ & 3 & .585 \\
Highest Academic Qualification & $3.911 \mathrm{a}$ & 4 & .418 \\
Teaching Experience & $8.036 \mathrm{a}$ & 2 & .018 \\
\hline
\end{tabular}

Chi-Square test was used to check whether there is any relationship between the respondents' characteristics and level of use of Elimika e-learning system. The result presented in table 2 shows little or no close association between the two factors.

Table 2. Relationship between respondent's characteristics and level of use of Elimika E-learning system

\begin{tabular}{cccc}
\hline Respondent's Characteristics & Value & df & Sig. \\
\hline Gender & $5.314 \mathrm{a}$ & 4 & .257 \\
Age & $11.284 \mathrm{a}$ & 12 & .505 \\
Highest Academic Qualification & $8.763 \mathrm{a}$ & 16 & .923 \\
Teaching Experience & $7.279 \mathrm{a}$ & 8 & .507 \\
\hline
\end{tabular}

A Correlation test was used to check whether there was any relationship between the respondents' gender, academic level, ease of use, interactivity and perceptions of Elimika system. The result is presented in table 3 below. 
Table 3. Correlation coefficients between Gender, Academic Level, Ease of Use, Interactivity and Perceptions of Elimika E-learning system

\begin{tabular}{ccccc}
\hline Spearman's Correlation Variable & Gender & Ease of use & Interactivity & Perceptions \\
\hline Academic Level & & & & \\
Correlation Coefficient & $0.119^{*}$ & 0.054 & -0.084 & $0.136^{*}$ \\
Sig. (2-tailed) & 0.047 & 0.366 & 0.161 & 0.024 \\
$\quad$ Ease of use & & & & -0.016 \\
Correlation Coefficient & 0.001 & $0.121^{*}$ & -0.046 & 0.794 \\
$\quad$ Sig. (2-tailed) & 0.986 & 0.045 & 0.447 & $-0.146^{*}$ \\
$\quad$ Interactivity & & & & 0.015 \\
Correlation Coefficient & 0.040 & -0.008 & 1.000 & \\
Sig. (2-tailed) & 0.505 & 0.893 &. & \\
\hline
\end{tabular}

$* * \mathrm{~N}=278$

Gender has a strong relationship with academic level at 0.047 significance, which is below 0.05 thus strong association. The academic level of the respondents determines strong perceptions (0.024) of the respondents on Elimika e-Learning System. The fact that Elimika system is easy to use makes it useful for curriculum orientation as exhibited by significance of $0.045<0.05$ which indicates a strong relationship.The Interactivity of the Elimika e-Learning system has a very strong bearing on the perceptions by the teachers and curriculum developers with significance at 0.015 with a negative skew.

\section{Summary of Key Findings}

The summary of the key findings of the study are presented below under each objective:

\section{i. To establish the extent of use of e-learning system by teachers in curriculum orientation programs.}

The findings obtained from this study show that Elimika e-learning system is extensively used by teachers for curriculum orientation. Most respondents perceived that the system is easy to use and interactive as it incorporates various multimedia elements such as text, audio, videos and animations. The results of study show that acceptance of e-learning depends on various critical factors. These are ease of use, level of use and interactivity of e-learning system. The study found out thatmajority (58.99\%) of the respondents were Males while $41.01 \%$ were of Female gender. Majority $(70.50 \%)$ of the respondents indicated that they found Elimika e-learning system easy to use with only $29.50 \%$ indicating that they found the system difficult to use. The fact that Elimika system is easy to use makes it useful for curriculum orientation as exhibited by correlation coefficient significance of $0.045<0.05$.

From the results of the Chi-Square test in chapter four, an analysis of relationship between the respondents' characteristics and ease of use of Elimika e-learning system showed significant relationships for gender (0.088) and teaching experience $(0.018)$ while age and highest academic qualification had little or no close association.This supports similar findings by Afari-Kumah and Achampong (2010) which found a positive relationship between experience and ease of use and no significant relationship with age and level of learners.

On interactivity of the e-learning system, most teachers felt that text, audio, videos, animations, practicing on topics taught, getting feedback and communication with tutors and fellow students was effective in curriculum orientation programs. This is probably as a result of Elimika platform's ability to combine various multimedia elements which enhances interactivity and hence success of the system in curriculum orientation.These findings confirms the observation by Odhiambo (2009) that interactive components such as interactive quizzes, animations, audio and feedback features help learners to effectively interact with and participate in the e-learning process.

\section{ii. To assess teachers' perceptions on the use of e-learning system in curriculum orientation.}

Perception of teachers shows that teachers found Elimika e-learning system enjoyable to use, understand how it works, is an effective learning tool, flexible, enhance learning experience, contain appropriate content, and integrate different aspects of the curriculum, saves money, time and effort. Teachers also agreed that Elimika system platform was easy to learn and navigate and instructions on use of the system were clear and detailed to understand.

From the analysis of correlation coefficients, the highest academic levels of the respondents determines strong perceptions of Elimika e-learning system at $0.024<0.05$. Also, the interactivity of the Elimika e-Learning system has a very strong bearing on the perceptions by the teachers and curriculum developers with significance of 0.015 with a negative skew. The findings of the study therefore shows that perception on Elimika e-learning system's worth, ease of use, ease of adoption and actual use reflects on teacher's understanding of curriculum. This is in agreement with Technology Acceptance Model (TAM) which postulates that a person's behavioural intention to use e-learning is determined by perceived usefulness and perceived ease of use (Davis, 1991).
iii. To identify the challenges encountered by teachers when using e-learning system in curriculum orientation programs. 
Majority of the respondents submitted that they face a range of challenges in utilizing Elimika e-learning system for curriculum orientation. Slow internet connectivity (19.51\%), Network down time $(18.70 \%)$ and Lack of computers $(12.20 \%)$ were the main challenges cited. The respondents also cited the following challenges in diminishing order: The program is expensive in terms of internet charge (8.13\%), Lack of adequate time to participate in Elimika program (7.32\%), Limited time for orientation to Elimika platform $(6.50 \%)$, Lack of electricity in some schools $(6.50 \%)$, Unclear systems instructions (4.07\%),Delays in getting feedback (3.25\%), Difficulties in communication when experiencing difficulties $(3.25 \%)$, Challenge in loading content to platform (3.25\%), Challenges in handling large number of participants during chats (3.25\%), Lack of appropriate content $(2.44 \%)$ and Poor ICT infrastructure in the country $(1.63 \%)$. These findings support the study by Kotrik and Redmann (2005) which revealed several challenges facing teachers in adopting e-learning technologies which included unreliable internet, availability of effective software, infrastructure, lack of enough time and inability for the teachers to effectively integrate technology. A study by Coleman (2011) also identified important barriers likely to affect the implementation of e-learning as poor internet connectivity, access to computers, lack of regular electric power supply, insufficient e-learning facilities, unfamiliar e-learning delivery modes, and low internet speed.

iv. To establish possible mechanisms that can be put in place to encourage teachers to use e-learning system in curriculum orientation programs

Majority (30.99\%) of the respondents recommended that there is need to allow time for teachers to be able to handle both the lessons they are teaching and E-Learning programs. The respondents also made the following recommendations in diminishing order: An affordable internet connection should be availed to schools ( $8.77 \%)$, Instructions should be clear and detailed (7.6\%), Add more content (5.26\%), The government should set aside funds to assist schools to source computers (4.68\%), Elimika website to have simple interface for fast loading in slow connections $(4.68 \%)$, More time for orientation to Elimika platform (4.68\%), Regular upgrade and content revision (4.09\%), Improvement of Country's ICT infrastructure (3.51\%), Upgrade system to accommodate all multimedia elements (3.51\%), The educational officers and the school administrators should be sensitized on the importance of the program $(2.92 \%)$, Elimika portal should be up and running all the time (2.92\%), Interface Elimika with cell phone alerts for effective communication $(2.92 \%)$, Link to TSC for promotion $(2.92 \%)$, Provide teachers with modems to save on internet down time (2.34\%), Purchase computer before enrolling for Elimika (2.34\%), Provide adequate infrastructure to enable teachers utilize the training (2.34\%), Have a call centre for full time support (1.75\%) and Build a redundant system with fail over strategies $(1.75 \%)$.

\section{Conclusion}

The following are the conclusions based on the analyses of the collected data: From the findings, Elimika e-learning system is extensively used by teachers for curriculum orientation. The system is also easy to use and interactive as it incorporates various multimedia elements such as text, audio, videos and animations. It saves money, time and effort; contains appropriate content and integrate different aspects of the curriculum.

Elimika e-learning system is enjoyable to use, understandable, effective and flexible. Its platform is easy to learn and navigate and instructions on use of the system are clear and detailed to understand. The findings indicate that Elimika system has a positive effect on the success of teacher orientation programs.

In spite of the benefits that will accrue to teachers and curriculum developers when e-learning is incorporated into teacher orientation programs, there are some challenges which need to be addressed. These include slow internet connectivity, network down time and lack of computers. Some recommendations put forward include provision of affordable internet connection, set aside funds for purchase of computers and allow time for teachers to be able to handle both the lessons they are teaching and E-Learning programs. Special efforts should also be made to target female students to use Elimika system for their curriculum orientation.

\section{Recommendations}

This study brought out a number of possible recommendations for future implementation: The study found out that among the challenges encountered by teachers are slow internet connectivity, network down time and lack of computers. The government and other stakeholders can provide enough computers and fast internet connection to schools to be used for e-learning. It is imperative to ensure that all schools are connected to electric power to facilitate use of computers and its associated accessories.

Allow time for teachers to be able to handle both the lessons they are teaching and E-Learning programs. A study leave given to teachers can go a long way in enabling teachers have ample time to concentrate on curriculum orientation programs.

To solve the problem of unclear systems instructions and slow feedback mechanism, KIE should ensure that online help and user guides are provided as well as clear and detailed instructions on the platform. A dedicated call centre for full time support should also be availed. Regular system upgrades, content revision and interfacing Elimika with mobile phone alerts will also have a positive impact on the success of Elimika e-learning system. 


\section{REFERENCES}

[1] Coldwell, J. et al (2008). Online Students: Relationships between Participation, Demographics and Academic Performance. The Electronic Journal of e-Learning.6(1), $30-34$.

[2] Meyen, E. et al. (2002). E-learning: a programmatic research construct for the future. Journal of Special Education Technology. 17(3), 102-104.

[3] Khan, B. (2005). Managing e-learning strategies: design, delivery, implementation andevaluation. Hershey, PA: Idea Group Inc.

[4] Kenya Institute of Education (2011). Elimika: Online Primary Teacher OrientationCourse. Nairobi: KIE Print and Publications.

[5] Davis, F. (1991). Perceived usefulness, perceived ease of use, and user acceptance ofinformation technology.MIS Quarterly. 13(3), 319-340.

[6] Fishbein, M. \&Ajzen, I. (1975). Belief, Attitude, Intention, and Behavior: AnIntroduction to Theory and Research. Reading, MA: Addison-Wesley.

[7] Jung, M. Loria, K. Mostaghel, R \&Saha, P. (2008). E-learning: Investigating UniversityStudents' Acceptance of Technology. European Journal of Open, Distance and E-Leaning. 23(1), 18-22.

[8] Kombo, D and Tromp, A. (2006): Proposal and Thesis Writing: an introduction. Nairobi: Paulines publications Africa.
[9] Mugenda, A. G. (2008). Social science research: theories and principles. Nairobi:Applied Research and Training Services.

[10] Orodho, A. \&Kombo, D. (2002). Research Methods. Nairobi: Kenyatta UniversityInstitute of Open Learning.

[11] Calmorin, L. et al. (2007). Research Methods and Thesis Writing. Manila: Rex Bookstore

[12] Creative Research Systems (2013). The Survey System Sample Size Calculator. AccessedJuly 222013 from http://www.surveysystem.com/sscalc

[13] Afari-Kumah, E \&Achampong, A. (2010). Modelling computer usage intentions of tertiary students in a developing country through the Technology Acceptance Model. International Journal of Education and Development using Information and Communication Technology (IJEDICT). 6(1), 1-15.

[14] Odhiambo, O.O. (2009). Comparative study of the E-learning platforms used in Kenyan Universities: A case study of Jomo Kenyatta University of Agriculture and Technology and United States International University Master's Thesis. Nairobi: Strathmore University.

[15] Kotrik, J.W. \&Redmann, D.H. (2005).Extent of Technology integration in instruction by Adult Basic Education teachers. Adult Education Quarterly. 2, 155-200.

[16] Coleman, R.K.N. (2011). Assessing the Adoption of E-Learning in Ghanaian Universities: Case of Some Ghanaian Universities. Master's Thesis. Skelleftea: Lulea University of Technology 